\title{
THE IMPACT OF SCHOOL EXPERIENCES ON STUDENTS' SENSE OF JUSTICE: AN INTERNATIONAL STUDY OF STUDENT VOICE ${ }^{1}$
}

\author{
STEPHEN GORARD \& EMMA SMITH \\ School of Education, University of Birmingham, UK
}

\begin{abstract}
This paper is based on a survey of 13,000 grade 9 students in five European countries. Using logistic regression analysis, it attempts to relate their aspirations, sense of justice, and trust in others, to their family backgrounds and experiences of schooling. Robust models emerge for the indicators of each of these three outcomes. Once individual student background is accounted for, parental involvement in education is no longer a relevant predictor. Students' reported treatment at the hands of other students and teachers at school, and the mix of student intake to their school, are the key predictors of adopting values such as tolerance of others. Schools with mixed intakes in terms of parental occupation, education, and country of origin have more aspirant and tolerant students, once the individual student background is factored in. This has implications for policy-makers. Schools in which students are treated with respect by teachers and other students have more trusting and generous students. This has implications for practitioners and practitioner bodies.
\end{abstract}

Key words: Equity, student voice, comparative education, logistic regression

\section{Introduction}

A key objective of education development is to increase participation and achievement among school students, especially those facing disadvantage in terms of language, poverty, ability and special needs. Another is to enhance their enjoyment of learning and their preparation for citizenship. Much education research concerns achievement and participation. But less effort has been put into considering how to promote enjoyment and 'good' citizenship, and how to recognise success or failure in this (EGREES, 2005). We add to knowledge in this area by looking at the impact of schools and student experience on how students might develop the civic 'values' of fairness, aspiration, and trust. We present the results of a new European survey of 13,000 15-year-olds, using an instrument assessing their experiences of justice at school, home and in wider society, their backgrounds, and their hopes for the future. Having introduced the topic and methods, the paper covers some of the findings before considering the possible implications of the

1 A project supported by the European Commission, Directorate General of Education and Culture, Project Socrates 2005-2434/001-001 SO2-61OBGE 
findings for school policies, and the behaviour of teachers.

This project looks at schools as organised societies and the part they play in creating among students a sense of justice and what is to be valued. For many students, their experience of school is fundamental to their conception of wider society, their place as citizens, and their sense of justice (Gorard, 2007a). One particular concern was to represent the views and experiences of potentially disadvantaged students, including those with learning difficulties, or behavioural problems, those apparently less suited to an academic 'trajectory', plus recent immigrants, those learning through a second language, or who are from socioeconomically deprived backgrounds. We know from previous studies (our own and the wider literature) that these indicators of potential disadvantage are strongly linked to individual student attainment (Gorard \& Smith, 2004a). But more generally it seems 'information about the position of the most disadvantaged groups in education is extremely scarce and fragmented. Genuine comparative research in this respect at the EU level is currently impossible because the basic information is not available' (Nicaise, 2000, p. 314). More research is needed on the effectiveness of school reforms in tackling educational and social exclusion. We considered it essential for the benefit of policy-makers and practitioners that we ask students and listen to their own accounts of school and wider experiences. Students have clear and coherent opinions, are willing to express them given a chance, and appear to be responsible commentators on a process of education that they are intimately involved in (Smith \& Gorard, 2006).

\section{Methods}

Our project ongoing has moved from a re-analysis of existing data sources at EU level (Gorard \& Smith, 2004b), through two large-scale pilot studies in five countries (EGREES, 2005), to the complex survey of (grade 9 students in 403 schools described in this paper. In the survey, there were around 80 schools each from Belgium, Czech Republic, England, France, and Italy. This yielded 12,575 complete cases, with a few missing or undefined responses allocated to the null category for each variable. The random sample of students was drawn from official lists of the schools in each country, via teaching units (classes). This was supplemented by a boosted sample of face-to-face structured interviews with students educated otherwise in hospitals, offenders' institution, and special schools. The grade- 9 students were intended to be around 14-years old at the time but, because of the grade repetition prevalent in some countries, the ages varied. This variation provided useful data for examining the possible impact of repetition on student views. The achieved sample was excellent, and representative of those students in each country facing potential disadvantage.

We collated existing official data about the intake, location, internal structure, governance and performance of these 403 schools where available. We supplemented these with a classroom-level questionnaire for the teaching staff, 
and with free-standing comments, observations and field notes taken during administration of the student survey. We use these various contextual sources as illustrations and potential explanations of the findings from the students. The student survey was piloted with 2,000 students in 100 classes in the same five countries - French-speaking Belgium, Czech Republic, England, France and Italy. This both assisted the main study and yielded useful data of its own (Gorard et al., 2007).

Part of our student questionnaire was built around questions intended to elicit responses about respondents' own principles of justice (Gorard \& Sundaram, 2008). We proposed that students would quite properly use different criteria (such as demand for autonomy, equal treatment, or equal opportunities) in different domains (EGREES, 2008, report to DG Education and Culture, available from the authors). We offered vignettes to students for them to consider how to act in a variety of situations, revealing the criteria of justice they might employ on each occasion. For example, we asked them to imagine a situation where a named student, with a plausible ethnic minority name, has trouble with reading. We offered students a range of options such it was fair that the named student got the same teacher attention as everyone, that the named student was offered more attention to help catch up even if this meant less attention for all others, or that the student should seek help outside school. The analysis below compares the students who were happy with the named student getting extra help with all other students. In addition, the student questionnaire asked about their family background (and key measures of disadvantage), their views on an ideal education, and their opinions on wider social issues such as crime, immigration and government. We examined their experiences and the potential impact of their experiences on well-being, work, relations at school, involvement in tasks, and results, plus perseverance in school, ethical and civic judgements, trust in institutions, and unfairness in general. The groupings selected to represent potential disadvantage include:

Those outside mainstream schooling

Differentiation by sex

Achieving low marks, low aspirations for future career, 'failed' at school or retained for one or more grade

Speaking a language other than that of the test country, moved to that country since birth, or parents had moved to that country

Parents had no job or a 'low' status occupation

Parents had not been to university (as a relatively comparable indicator of education across the five countries).

The data have been analysed in terms of frequencies and cross-referenced. We have described differences in outcomes and experiences between socio-economic and ethnic groups, countries and school types (EGREES, 2008). These initial results were presented to an international audience of teachers, school leaders and teacher trainers for discussion and feedback both on the presentation of results 
and on further analyses to be conducted. The comments and concerns of these practitioners have been integrated into our analysis as far as possible.

We have also modelled the plausible social and educational determinants of the different perceptions of justice among different types of students. In the models, variables were classified in terms of background (e.g. student sex), predictors (e.g. experience of justice), and potential outcome variables (e.g. sense of justice). This enables'prediction' of the outcome variables using both background and experience variables to assess the influence of family and school on students' developing sense of justice. The three models presented in this paper are derived from logistic regression analysis with binary 'dependent' variables - professional aspiration, trust, and help for the disadvantaged. In each case, around $50 \%$ of students were in each category (wanted a professional occupation or not, were willing to trust most people or not, were willing for a student with difficulties to receive extra help at their expense or not). And in each case the regression analysis used the other 'independent' variables to predict which category a student would have chosen, so increasing the accuracy from around $50 \%$ to around $70 \%$ (so explaining $40 \%$ of the residual variation). The independent variables were entered in six blocks representing student background (such as parental occupation), aggregated (i.e. school-level) background, parental support (such as whether parents talked to children about schooling), aggregated parental support, experience of justice at school (such as whether students were bullied), and aggregated experience of justice. The stages represent a rough biographical order, and so protect the analysis from the invalid influence of later proxies (such as success at school replacing parental education). This is the method introduced by Gorard et al. (1998), developed by Gorard \& Selwyn (2005), and now adopted by others (e.g. Antikainen $\&$ Huusko, 2008).

The 'aggregated' variables are the percentage of students in each school sample reporting the first response in each classification, or agreeing with the statement in the questionnaire. All other variables are categorical, and results are reported using indicator coding with the last category as the referent. Variables were selected within each stage by means of backward stepwise elimination (likelihood). Those eliminated were deemed irrelevant as they did not affect the quality of the result once other variables had been taken into account. As with all such models, these do not represent any kind of definitive test but are a way of filtering the results to see potential patterns.

In two countries (France and England) a very high proportion of students have no reported job aspiration (a defect of the machine-reading and coding of forms), and this proportion might distort the results (making country appear a good predictor). Therefore, country of student is omitted as a predictor from the analysis of aspiration (rather than omitting this large number of cases). Some variables were specific to each country and these are also omitted. The estimate of the schoollevel data is derived from the sample here, because the school-level data collected from each school is too varied in quality. There is no universal objective indicator of 
student attainment. Here we use student self-report of attainment, and this does lead to some problems of interpretation (see below).

Given the inevitable imprecision of the measurements involved in this international postal survey, it would be unwise to focus on any small increases in correctly predicting aspiration or on variables having only a minor impact on the results. Because the original sample required some replacement of cases due to non-response, it is no longer considered a random representation of each country and so the issue of significance ( $p$-values) is no longer relevant. The findings below are described in relation to the very large sample itself.

The paper describes three modelled outcomes in turn - occupational aspiration, a criterion of justice, and willingness to trust others.

\section{Predicting professional aspiration}

Professional aspiration was used as the dependent variable in a binary logistic regression. In total, $48 \%$ of students reported wanting a professional occupation after leaving education, and the remaining $52 \%$ did not. Any prediction of an individual student aspiration to a professional occupation would be $52 \%$ correct simply by assuming that no on wished to be a professional. The success of the model depends on its ability to improve on this baseline figure. The percentage predicted correctly in terms of logistic regression for each stage of the model is in Table 1.

Table 1: Percentage of students correctly allocated to professional aspiration or not, by batch of variables

\begin{tabular}{|l|c|c|}
\hline Batch & $\begin{array}{c}\text { Percentage predicted } \\
\text { correctly }\end{array}$ & $\begin{array}{c}\text { Percentage of } \\
\text { remaining variation } \\
\text { explained }\end{array}$ \\
\hline base figure & 52 & - \\
\hline student background & 64 & 25 \\
\hline aggregated background & 69 & 10 \\
\hline parental support & 69 & 0 \\
\hline aggregated parental support & 69 & 0 \\
\hline experience of justice at school & 71 & 4 \\
\hline aggregated experience of justice & 71 & 0 \\
\hline
\end{tabular}

As can be seen, the model is reasonably successful in predicting aspiration over and above the baseline figure, especially given the likely variation in occupational structure between countries which cannot be picked up here because of the huge difference in response rates between countries (see above). A further 19\% (over and above 52\%) is explained in total. Of this increase, almost all is accounted for by student background characteristics, and school-level figures for student background (the school mix). A small amount of the remaining variation is accounted for by 
students reported experience of justice at school.

Of the student background factors, once other characteristics are taken into account, whether the student was born in the country of the survey or not, and whether their parents were born in the survey country, are not relevant to aspiration. This suggests fairness of a kind, in that those students born outside the country of the survey or with one or more parents born elsewhere have the same level of professional aspiration as 'indigenous' students.

The most important predictor of aspiration is (self-reported) level of attainment at school-used as an indicator of academic talent. Students reporting high attainment are 2.39 times as likely as those reporting low attainment to want a professional occupation, ceteris paribus. Similarly, students reporting average attainment are 1.57 times as likely as low attainers to want a professional occupation. So, one interpretation is that low attaining students have lower occupational aspirations. Where we have been able to verify these self-reports with Key Stage results (for the England sample), they are reasonably accurate. However, it is also possible that both of these subjective variables are simply picking up the same level of confidence in self-reports.

If attainment is put aside for this reason, the most important influence on aspiration is, unsurprisingly, the occupation of parents. For example, 59\% of students with professional fathers also want a professional career, compared to $45 \%$ for children of skilled worker fathers, and $41 \%$ for children of those in unskilled or no employment.

Students with professional mothers are 1.38, and professional fathers 1.58 , times as likely to report professional aspirations. Those with semi-professional mothers are 1.27 times and semi-professional fathers 1.05 . It is unclear from this survey whether this is a kind of direct reproduction or whether there are latent forms of capital in professional families that lead to higher aspiration among children. Lesser influences are sex (females 1.09 times as likely as males), first language (those speaking home language 1.10 times), and father attending university (1.14). Mother attending university is not relevant for this generation.

When the student background variables are aggregated to the school level, as an estimate of the school mix effect of clustering similar students in schools and classes, they can further improve the predictions of aspirations. One interpretation of this is that there is a school mix effect on student aspiration. So, for example, as well as the student's father's occupation being a good predictor (see above), the percentage of professional fathers in each school is also a good predictor. In fact, the odds of aspiring to a professional occupation increase 1.02 times for each percentage of the school intake with professional fathers. This is a very large increase in addition to the impact of the student's own father. The mother's occupation is slightly less important than father's for the school mix (1.01), but where they were born is somewhat more important. The odds of aspiring to a professional occupation increase 1.03 times for each percentage of the school intake with mothers born in the survey country. Or put another way, while the country of origin of each student is not apparently relevant to their aspirations, having schools with 
high concentrations of students with mothers from another country reduces aspirations. Where the student and the father were born does not seem to matter so much once the origin of the mother is taken into account. The odds of aspiring to a professional occupation increase 1.01 times for each percentage of the school intake speaking the language of the survey country at home, regardless of the language spoken by an individual student.

Those attending school with a high percentage of students from professional, educated families tend to have higher aspirations even where they are from different kinds of families themselves. If accepted, this finding has a clear message for the promotion of social justice via the school mix. Allowing students from professional, educated families to cluster in specific schools will encourage social reproduction. There is no gain in such clustering, since there is no clear school mix on attainment (Gorard, 2006a). There is a cost in terms of social mobility. Thus, as with many analyses, but this time in terms of social justice, we conclude that comprehensive and undifferentiated schools are the best as a system (Gorard, 2007b). Education cannot directly influence inequalities in student background. But the allocation of school places is generally a lever that is under the direct control of central and local government.

The clustering of parents who have been to university is not relevant once these other factors are taken into account. More importantly from a policy perspective, the backwards stepwise regression also eliminated the percentage of boys and girls and the percentage of high, average and low attainment students as predictors. Thus, as far as we can tell from this survey, putting girls (and boys) in separate schools does not influence their aspiration once their background is factored in. Similarly, selecting students to school by (self-reported) attainment neither increases nor decreases their aspiration. It is socio-economic segregation between schools that matters here.

The survey included four questions about the student's relationship with parents, and the kinds of interest and support their parents provided. Using these variables makes no difference to the quality of the prediction and all four items are eliminated in backward stepwise selection - both individually and aggregated to school level.

There is a small but discernible relationship, once the preceding factors are accounted for, between students' reports of experiencing justice in school and their aspirations. While background is very important and school structure (such as segregation) is important in producing aspiration, there is still a small role for the interaction of teachers and students at school. In terms of policy, an interesting result in terms of student experience is that whether a student repeats a year or more (i.e. born before 1991) makes no difference to aspiration (ceteris paribus).

Students strongly disagreeing that they get on well with teachers are much less likely to report wanting a professional occupation (Table 2 ). Those strongly agreeing were 1.30 times as likely as those strongly disagreeing to want a professional occupation. If there is any causal link here it is unclear. It might be that teachers have a role in reducing the hopes of some students. Students strongly agreeing that 
teachers respected their own opinions even when they differed in opinions were 1.25 times as likely as those strongly disagreeing to want a professional occupation. These two items both relate to the individual student and their relationship with teachers. Those students with professional aspiration tend to report better personal relationships with teachers.

However, the opposite is true when they consider student:teacher relationships in general. Students with professional aspirations tend to identify the unfair treatment of other students. Those strongly agreeing that teachers respected all students' opinions even when disagreeing were less likely to have professional aspirations $(0.88)$ than those strongly disagreeing. Similarly, those strongly disagreeing that all students were treated the same had the highest aspirations. Again, those strongly disagreeing that they trusted teachers to be fair had the highest aspirations (0.84).

Table 2: Coefficients for student/school experience variables

\begin{tabular}{|l|l|l|l|l|}
\hline & $\begin{array}{l}\text { Strongly } \\
\text { agree }\end{array}$ & Agree & Neither & Disagree \\
\hline Get on well with teachers & 1.30 & 1.33 & 1.16 & 1.15 \\
\hline $\begin{array}{l}\text { Teachers respect my opinions even } \\
\text { when we disagree }\end{array}$ & 1.25 & 1.02 & 1.03 & 0.99 \\
\hline Teachers respect all student opinions & 0.88 & 1.07 & 1.07 & 1.15 \\
\hline Teachers treated all students the same & 1.02 & 0.81 & 0.93 & 0.92 \\
\hline Teachers can be trusted to be fair & 0.84 & 1.01 & 0.91 & 0.90 \\
\hline Good friends at school & 1.72 & 1.82 & 1.54 & 2.22 \\
\hline Discouraged easily & 0.95 & 0.83 & 0.90 & 0.99 \\
\hline Friends with low marks & 1.05 & 0.99 & 0.84 & 0.85 \\
\hline School was a waste of time & 0.47 & 0.58 & 0.60 & 0.84 \\
\hline
\end{tabular}

Note: all coefficients are in relation to the strongly disagree category

Those strongly disagreeing that they had good friends at school had the lowest aspirations. Those strongly agreeing were 1.72 times as likely to want a professional job. The other odds were agree (1.82), neither (1.54) and disagree (2.22). Those strongly disagreeing that they were discouraged easily had the highest aspirations. Those strongly disagreeing that they had friends who got low marks at school had the highest aspirations. The other odds were strongly agree (1.05), agree (0.99), neither (0.84) and disagree (0.85). Those strongly disagreeing that school was a waste of time had the highest aspirations. The other odds were strongly agree (0.47), agree (0.58), neither (0.60) and disagree (0.84). However, the model was also run with this last variable omitted on theoretical grounds. It could be interpreted as an outcome of schooling as well as an experience. In general, those with the most positive personal experience of school had the highest aspirations (or vice versa of course). So there is an important role for schools in the creation of future aspirations, perhaps especially in the interaction between students. 


\section{Predicting criterion of justice}

Whether teachers should give more help to a student with reading difficulty or not was used as the dependent variable in a binary logistic regression. In total, 51\% of students reported that the teacher should give extra help to a student with a specific difficulty, and the remaining $49 \%$ did not. Any prediction of an individual student happy for more help to be given to a student with a difficulty would be $51 \%$ correct simply assuming that everyone was happy with it. The success of the model depends on its ability to improve on this baseline figure. The percentage predicted correctly for each stage of the model is in Table 3. The model increases the accuracy of prediction, compared to the baseline, by $20 \%$. Of this increase, nearly half is attributable to the student background, and half to experiences at school. There is only a small school mix effect, and most of the variation explained operates at the individual level.

Table 3: Percentage of students correctly allocated to help criterion of justice or not, by batch of variables

\begin{tabular}{|l|c|c|}
\hline Batch & $\begin{array}{c}\text { Percentage predicted } \\
\text { correctly }\end{array}$ & $\begin{array}{c}\text { Percentage of } \\
\text { remaining variation } \\
\text { explained }\end{array}$ \\
\hline base figure & 51 & - \\
\hline student background & 60 & 18 \\
\hline aggregated background & 61 & 2 \\
\hline parental support & 61 & 0 \\
\hline aggregated parental support & 61 & 0 \\
\hline experience of justice at school & 70 & 18 \\
\hline $\begin{array}{l}\text { aggregated experience of } \\
\text { justice }\end{array}$ & 71 & 2 \\
\hline
\end{tabular}

Note: For comparison purposes, we used the same variables to 'predict' an entirely random binary outcome to assess the dangers of fitting the model post hoc. The best such model is around $54 \%$ correct, meaning that a lot of the variance explained in tables like this one is unlikely to be spurious.

Insofar as we can explain student willingness for others to get extra help, student background is a factor, although the sex, attainment, and country of origin of the student are irrelevant to this criterion of justice. Also irrelevant are the occupations, education and country of origin of parents. Those living in England are more likely to approve of help given to others than those in Belgium (0.92), Czech Republic (0.95), France (1.00) and Italy (1.00). This is illustrated in the percentages agreeing with extra help, when this variable is looked at in isolation. The raw figures are England (72\%), Belgium (59\%), Czech Republic (44\%), France (51\%) and Italy (36\%). In addition, given that the vignette is about difficulty in reading, it is interesting 
that those speaking the language of the survey country are generally happier for a student struggling with reading to be given extra help (1.26).

There is a small improvement in correct predictions if the student background variables are aggregated to the school level as an estimate of the school mix effect of clustering similar students in schools and classes. Schools with higher proportions of students born in the survey country are less likely to be happy with extra help given to others. Support for the criterion declines by 0.99 for every percentage of indigenous students.

The survey included four questions about the student's relationship with parents. Using these variables at individual or school level makes no difference to the quality of the prediction (just as with aspiration).

A large number of school experience variables are not relevant to increasing the quality of the prediction, including whether a student repeats a year or more (i.e. born before 1991). But there is a very clear relationship, once the preceding factors are accounted for, between students' reports of justice in school and their willingness for a student in difficulty to receive extra help.

Being respected by teachers, with teachers not getting angry in front of others, not punishing students unfairly, concerned for student well-being and prepared to explain until everyone understands, are key to students learning to support help for those with difficulties (or reporting this at least). Taken at face value this suggests a clear role for teachers in educating citizens who are tolerant and supportive of the difficulties of others (Table 4). They do this not only (or perhaps at all) through citizenship pedagogy but through their exemplification of good citizenship in action (Gorard, 2007a, 2007b). There is similarly a key role for the students. Having friends is important, and also avoidance of being mistreated by other students. Those reporting being hurt, bullied and having things stolen by other students at school are all less likely to support extra help for others. This is not a school mix effect (e.g. where those attending schools with low levels of theft are more supportive anyway). Thus, it appears to stem directly from treatment by others. Some of the differences are slight. For example, $44 \%$ of students who had been clearly bullied were in support of help for others, compared to $51 \%$ who had clearly not been bullied. Nevertheless, there could also be a role for teachers here then, in preventing such mistreatment and educating the potential bullies and thieves. 
Table 4: Coefficients for student/school experience variables

\begin{tabular}{|l|c|c|c|c|}
\hline & $\begin{array}{c}\text { Strongly } \\
\text { agree }\end{array}$ & Agree & Neither & Disagree \\
\hline Teachers respected my opinion & 1.03 & 1.11 & 1.21 & 0.98 \\
\hline Teachers interested in my well-being & 1.27 & 1.00 & 1.10 & 1.07 \\
\hline I have good friends in school & 1.70 & 1.70 & 1.82 & 2.38 \\
\hline Something of mine stolen & 1.02 & 1.18 & 1.14 & 0.98 \\
\hline I was deliberately hurt & 1.18 & 0.91 & 1.08 & 0.87 \\
\hline I got discouraged easily & 1.06 & 0.93 & 1.01 & 0.97 \\
\hline Teachers got angry with a student & 0.81 & 0.89 & 0.94 & 0.98 \\
\hline Teachers continued explaining & 0.98 & 1.06 & 1.01 & 0.94 \\
\hline Teachers punished fairly & 0.81 & 0.68 & 0.74 & 0.80 \\
\hline
\end{tabular}

Note: all coefficients are in relation to the strongly disagree category

\section{Predicting levels of trust}

Whether most people can be trusted was the third outcome used as the dependent variable in a binary logistic regression. In total, $51 \%$ of students reported not trusting people generally, and the remaining $49 \%$ trusted people to some extent. Any prediction of an individual student trusting people would be $51 \%$ correct simply assuming that no one trusted people. The success of the model depends on its ability to improve on this baseline figure. The percentage predicted correctly for each stage of the model is in Table 5.

Table 5: Percentage of students correctly allocated to trusting people or not, by batch of variables

\begin{tabular}{|l|c|c|}
\hline Batch & $\begin{array}{c}\text { Percentage } \\
\text { predicted correctly }\end{array}$ & $\begin{array}{c}\text { Percentage of } \\
\text { remaining variation } \\
\text { explained }\end{array}$ \\
\hline base figure & 51 & - \\
\hline student background & 56 & 10 \\
\hline aggregated background & 56 & 0 \\
\hline parental support & 57 & 2 \\
\hline aggregated parental support & 57 & 0 \\
\hline experience of justice at school & 62 & 10 \\
\hline aggregated experience of justice & 64 & 4 \\
\hline
\end{tabular}

Student background characteristics explain some of the variation in outcomes but not as much as might be expected. And this influence mostly operates at the individual level, with no evidence of a school mix effect. Of the increase of $13 \%$ 
in correct predictions over and above the baseline, over half is attributable to experiences of justice at school. This is after background and parental support have been taken into account, and so represents reasonable evidence of the influence of school.

Insofar as we can explain a tendency to trust people with these survey data, student background is a factor. However, the sex, language, country of origin of the student, and the occupations of parents, are irrelevant to this issue of learning to trust most people. Those students living in England are slightly more trusting than those in Belgium (0.99), Czech Republic (0.98), France (0.99) and Italy (0.98). Those with a father born in the survey country are also slightly more trusting (1.08). However the main determinant of this improvement in the baseline model lies in the (self-reported) attainment of students. Intriguingly, students reporting higher levels of attainment at school are somewhat less likely to report trust (0.94) than average attainers who are in turn less likely than low attainers (1.05). Whether this is due to greater perspicacity, or another confounding variable, is not clear.

The survey included four questions about the student's relationship with parents. Using these variables makes a small difference to the quality of the prediction. Parents talking to students about their friends and interests, and being interested in their well-being, are irrelevant here. Those whose parents treat them with respect and talk to them about school tend to be more trusting. Those who strongly agree that their parents treat them with respect have relative odds of 1.13, agree 1.20, neither 0.97 and disagree 0.90 . Those who strongly agree that their parents talk to them about school have relative odds of 1.12, agree 1.19, neither 1.06 and disagree 0.91. This suggests a role for parents in the exemplification and formation of trust.

There is a very clear relationship, once the preceding factors are accounted for, between students' reports of justice in school and their sense of trust in other people. While background is important in producing trust, the biggest factor among the items surveyed is the reported interaction with teachers and students at school. Unlike aspirations, whether a student repeats a year or more (i.e. born before 1991) makes a difference to trust (0.93).

Those who report getting along well with their teachers, and trusting their teachers to be fair, are more trusting in general. Of course, there is a possible element of tautology in several of these'independent'variables. Students who have repeated one or more years are less likely to be trusting (41\%) than those who have not $(50 \%)$, perhaps linked to the lack of grade repetition in England. However, it is actual experiences at school that are most strongly related to trust. Students who regard school and teachers as fair, and the meting out of punishments as fair, and who have not been hurt or isolated by other students nor had something stolen are, perhaps understandably, more trusting. As with the help outcome, this suggests a clear role for teachers in educating citizens who are generally trusting of others. They do this through their exemplification of good (or indeed poor) citizenship in action. There is also a role for teachers in preventing the mistreatment of some students by others and educating any potential 'bullies' or 'thieves' (Table 6). 
Table 6: Coefficients for student/school experience variables

\begin{tabular}{|l|c|c|c|c|}
\hline & $\begin{array}{c}\text { Strongly } \\
\text { agree }\end{array}$ & Agree & Neither & Disagree \\
\hline Got along well with teachers & 1.08 & 1.12 & 1.10 & 0.82 \\
\hline Trust teachers to be fair & 1.17 & 1.12 & 1.02 & 0.86 \\
\hline Felt invisible to mates & 0.86 & 1.15 & 1.09 & 1.14 \\
\hline Something stolen & 0.89 & 0.87 & 1.02 & 0.92 \\
\hline Deliberately hurt & 0.81 & 1.0 & 1.07 & 1.14 \\
\hline Discouraged easily & 0.82 & 0.82 & 0.85 & 0.92 \\
\hline Friend from abroad & 1.09 & 1.13 & 1.07 & 1.10 \\
\hline Friend with low marks & 1.14 & 1.04 & 1.18 & 0.90 \\
\hline All students treated same way & 1.10 & 1.07 & 1.07 & 0.98 \\
\hline Teachers got angry & 0.86 & 0.95 & 0.95 & 1.00 \\
\hline Teachers punished fairly & 1.23 & 1.27 & 1.27 & 1.14 \\
\hline Student marks deserved & 0.97 & 1.12 & 1.12 & 0.88 \\
\hline School was fair & 1.40 & 1.35 & 1.23 & 0.87 \\
\hline
\end{tabular}

Avoidance of bullying, personal violence, and theft are related to learning to trust others - or put the other way, the least trusting are those who have been victims of bullying, violence, and theft at school. Therefore, there is an argument that what happens at school differentially influences students' sense of what is just and fair, and what wider society is like. And a lot of what happens is the direct responsibility of other students, while only indirectly due to the (in)actions of teachers. If citizenship education entails learning appropriate levels of trust in others, then the level of reported mistreating of students by other students is a clear barrier to progress.

\section{Discussion}

It is important to recall that a lot of potentially important things remain unmeasured in our survey of students. The school level characteristics, for example, have had to be estimated by simply aggregating the responses of those students who respond. In addition, we cannot claim that the samples are perfectly representative, nor the questions perfectly phrased for each language, and there is inevitably some non-response. Most importantly, we are associating some parts of the reports of students with other parts of the same reports. There is no test of a causal model here, and even a danger of elements of tautology in some findings.

Nevertheless, the scale of relationship between the predictors such as student background, school mix or student experience of justice, and the outcome variables trialled here is substantial, over a large sample across five countries. The results are credible. Another way of imagining these findings is to contrast them with the long-standing work on academic school effectiveness. School effectiveness, as a 
field, has the same problems as the work described here. It is not a causal test, does not have complete information, has to deal with omitted variables and missing cases, and so on.

In one crucial respect, school effectiveness models are stronger and more impressive than those described here. They are capable of explaining between $80 \%$ and $100 \%$ of the variation in student academic outcomes simply in terms of background data, such as student prior attainment (Gorard, 2006b). The attainment of students in schools is largely predicated on their prior attainment and background characteristics. In developed countries, it does not appear to make much difference which school a student attends. Going to school obviously makes some difference in comparison to not going to school but little difference in comparison to going to a different school in the same system. Almost all schools are free, compulsory, roughly equal in funding, inspected, with trained staff, widely shared curricula, and standardised tests. There is very little variation (0 to 20\%) left to attribute to the differential impact of schools, and this 0 to $20 \%$ includes the error components contributed by inevitable flaws in the research and measurement (see above). There is almost certainly not enough variation remaining to identify a school mix effect on attainment (Gorard, 2006a).

In contrast, the models described here explain only about $20 \%(10 / 50)$ of the variation in student 'justice' outcomes using student background data alone. The main reason for this is that unlike school effectiveness work we do not have a prior score for student sense of justice. We do not know, therefore, how much (or little) students' sense of justice has changed since their arrival in secondary-age school. In school effectiveness work it has become traditional simply to ignore the error component and attribute all variation in outcomes left unexplained by student background to the 'school effect'. It is in this respect that our model here is stronger. There remains $60 \%(30 / 50)$ variation in outcomes, and we leave this unattributed (except to error and flaws in the research). But the school mix (for aspiration) and school experience variables (for help and trust) actually explain a further $20 \%$. They are modelled in biographical order (and so the time sequence necessary for causation), rather than the nesting hierarchies used in school effectiveness, which perforce ignore characteristics that do not nest such as sex or parental support. This is a more powerful finding than the school effects purportedly found in school effectiveness work. Thus, it is worth thinking about the consequences of.

The use of school improvement models has led, indirectly, to an overemphasis on the most visible indicators of schooling - examination and test scores. The use of test scores leads to three related problems. It may marginalise other purposes and potential benefits of schooling. In addition, it suggests that variations in the scores themselves are largely the product of school effects when the evidence clearly shows otherwise. It also neglects the fact that the scores themselves are artificial, and technically difficult to compare fairly over time or place. The mix of students within schools has implications for their raw-score standards of achievement (note, for example, that all schools deemed 'failing' in the UK have high levels of student poverty). But, in general, the lessons from PISA and other international studies 
are that mixing students between schools whether in terms of occupational class, income, or sex, leads to no depreciation in attainment (Haahr et al., 2005).

Equity is difficult to define but represents that sense of fairness which underlies our decisions about the principles of justice to apply in different domains for a given set of actors. In specific situations there is considerable agreement, among students, about what is fair and what is unfair. Equity is an important ideal for education, in terms of school as a lived experience as well as its longer-term outcomes for citizens and society. Students have quite clear views on what is fair, and are generally willing and able to express those views. Are research users willing to acknowledge and act on those views? We summarise here some of the early possible conclusions from this new study for policy-makers, practitioners and researchers.

In general there is a high level of equality in the responses across all countries and indicators of disadvantage. This is highly encouraging, since even if we were to conclude that some students are objectively disadvantaged, the students themselves are not aware of this or are not treated in any systematically inferior way. In fact those outside mainstream schooling were in many ways the most positive about their treatment and experiences. They often felt respected and cared for in appropriate ways. However, the number of cases was small and this is an important strand for future in-depth research. Very few students see school as a waste of time.

There is little impact of school experience on aspiration (although of course this could be due to missing variables). This finding confirms a number of recent international syntheses of evidence on the importance of a mixed intake to schools (comprehensive rather than selective, for example) for both efficiency and equity of attainment. It adds to that the key message that school mix also relates to subsequent aspirations. This could affect patterns of post-compulsory participation and attainment as well (Gorard et al., 2007). School experience combines with social background to form a relatively permanent learner or nonlearner identity (Gorard \& Selwyn, 2005). What is true for aspirations appears also to be true for post-compulsory participation in education or training (Gorard \& Smith, 2007). Clustering students in schools by socio-economic, whether deliberately or not, reduces the educational as well as the occupational aspirations of the most disadvantaged. In general, students reporting a positive experience of school (not bullied, treated with respect by teachers) have more professional aspirations (or vice versa of course).

However, as we have shown here, clustering students with similar backgrounds in schools tends to strengthen social reproduction over generations. With the potential determinants of these outcomes modelled in lifelong order, future aspiration is not particularly influenced by experiences of justice at school. Rather, it is here that the school mix has its greatest impact. The implications for policy are clear. To raise occupational and educational aspirations of the most disadvantaged in society a mixed school intake is desirable. If we wish disadvantaged students to raise their educational and occupational aspirations, one simple lever under our control is the policy of allocating students to schools. A mixed, comprehensive 
and undifferentiated system of schools is preferable in this regard to a tracked, selective, faith-based or specialist one. Socially segregated systems are unfair to the most disadvantaged and are at best zero-sum for attainment, in comparison to comprehensive systems.

Students in more comprehensive systems, who speak the language of their country of residence as a first language, are also more content that extra help is given to struggling students - even when this help means that they may have less attention. If struggling students themselves are taken out of the analysis, ironically support becomes stronger. Thus, there is widespread but not universal support for a principle of fairness other than equal treatment for all.

Fairness for individuals, a sense of justice, and social cohesion are as much a product of experiences in schools, as lived in, as they are of the formal educational process. Social, ethnic and economic segregation matters, but not primarily for the sake of test results. It does not make sense to have a society preaching racial tolerance within a racially segregated school system, for example. For students their schools are their life, and not merely a preparation for it. Equity in schools matters for today, for the range of experiences of each student, for social cohesion, and to allow schools to teach important aspects of citizenship without being open to the charge of being hypocritical.

Immigrants generally report being well treated, and are as likely as others to have good friends, good relationships with teachers, and hopes for the future. There is a far smaller proportion of recent immigrants in the Czech Republic and their responses and those of other to them are slightly different. There is less integration (friendship patterns) of recent immigrants there. Students in the Czech Republic are more supportive of new immigrants having to adopt the cultures and tradition of the host country. While the figures are low, it is clear that immigrants in Italy report substantially more negative episodes such as being bullied or hurt by other students. There are concerning levels of reported bullying of students by other students in England, especially among the lowest achievers (30\% of low achievers reported being deliberately hurt by another student).

Once family background is accounted for, there is a clear impact of students' experiences of school on students' sense of justice. As may be imagined, those treated best at school tend to have the most positive outlook on trust, civic values and sense of justice. Perhaps the biggest threat here lies in the actions of other students, and so any (in)actions of teachers to prevent bullying, stealing and violence.

Teachers were not always perceived to be treating students fairly and consistently. There is a difference here between the personal experience of the students, and their perception of the treatment of a minority of others. A common view was that teachers had students who were their favourites, that rewards and punishments were not always applied fairly, and that certain groups of students were treated less fairly than others. How can a curriculum for citizenship, which embraces issues of fairness and democracy, be effectively implemented if the students themselves do not mostly believe that their teachers are generally capable of such behaviour? 
In one sense, it does not really matter what the curriculum states about citizenship compared to the importance for students of experiencing mixed ethnic, sex and religious groups in non-racist and non-sexist settings, and of genuine participation in the decision-making of the schools

A similar conclusion comes from consideration of learning to trust other people. Most students do not trust their government. This is especially so in the Czech Republic. Most students do not trust adults in general, and have learnt to be cautious in dealing with them. There is widespread agreement that all students should be treated with respect by teachers, their opinions valued, and not humiliated in any way. Teachers can help produce positive citizens both through the respect with which they treat students and in the way that they act to prevent the mistreatment of some students by others.

Students are happy for their assessed work to be discriminated in terms of quality and effort, but they complain that hard-working, high-attaining should not otherwise be favoured by teachers. This is a clear and strict application of the principle of merit, and one which teachers are apparently generalising from and so misusing. Students were able to give clear examples of injustice and of the principles they used to identify injustice. In schools there is a clear mismatch between what students want and what they experience, in several ways. These include students wanting their opinions respected even when the teacher disagrees; few report this. Students want teachers to continue explaining topics until everyone understands; few report this. Students want marks to reflect quality of work; many do not report this happening. Students do not want hard-working students to be favoured (except in assessment terms); most report the opposite.

The most important lever under our control to encourage support for the more disadvantaged relates to behaviour in schools. Schools and classes that are respectful, fair, and intolerant of bullying tend to have more supportive students. Citizenship is not merely a subject in schools, it must be a way of life.

\section{References}

Antikainen, A. \& Huusko, A. (2008). The impact of information technology on participation in adult education: the case of Finland from a comparative perspective, International Journal of Contemporary Sociology, 45 (2), 119-129.

European Group for Research on Equity in Educational Systems. (2005). Equity in European Educational Systems: a set of indicators, European Educational Research Journal, 4 (2), 1-151.

European Group for Research on Equity in Educational Systems. (2008). Developing a sense of justice among disadvantaged students: the role of schools. Birmingham: European Group for Research on Equity in Education Systems.

Gorard, S. (2006a). Is there a school mix effect? Educational Review, 58 (1), 87-94.

Gorard, S. (2006b). Value-added is of little value. Journal of Educational Policy, 21(2), 233-241.

Gorard, S. (2007a). Justice et equite a l'ecole: ce qu'en dissent les eleves dans les 
etudes internationales. Revue Internationale d'Education Sevres, 44, 79-84.

Gorard, S. (2007b). The true impact of school diversity. International Journal for Education Law and Policy, 2(1-2), 35-40.

Gorard, S. \& Selwyn, N. (2005). What makes a lifelong learner? Teachers College Record, 107(6), 1193-1216.

Gorard, S. \& Smith, E. (2004a). What is 'underachievement' at school? School Leadership and Management, 24(2), 205-225.

Gorard, S. \& Smith, E. (2004b). An international comparison of equity in education systems? Comparative Education, 40(1), 16-28.

Gorard, S. \& Smith, E. (2007). Do barriers get in the way? A review of the determinants of post-16 participation. Research in Post-Compulsory Education, 12(2), 141-158.

Gorard, S. \& Sundaram, V. (2008). Equity and its relationship to citizenship education. In J. Arthur, I. Davies, \& C. Hahn (Eds.) The Sage Handbook of Education for Citizenship and Democracy. (p.71-79) London: Sage.

Gorard, S., Rees, G., Fevre, R., \& Furlong, J. (1998). Learning trajectories: Travelling towards a learning society? International Journal of Lifelong Education, 17(6), 400-410.

Gorard, S., with Adnett, N., May, H., Slack, K., Smith, E. \& Thomas, L. (2007). Overcoming barriers to HE. Stoke-on-Trent: Trentham Books.

Haahr, J., with Nielsen, T., Hansen, E., \& Jakobsen, S. (2005). Explaining student performance: evidence from the international PISA, TIMSS and PIRLS surveys, Danish Technological Institute, www.danishtechnology.dk, accessed August 2005

Nicaise, J., Straeten, M., Baye, A., \& Demeuse, M. (2005). Comment développer un système d'indicateurs d'équité au niveau européen? In M. Demeuse, A. Baye, M.H. Straeten, J. Nicaise, \& A. Matoul (Eds.) Vers une école juste et efficace. 26 contributions sur les systèmes d'enseignement et de formation. (p. 337-353). Bruxelles: De Boeck.

Smith, E. \& Gorard, S. (2006). Students' views of equity in education, Compare, 36(1), 41-56. 